\title{
Effect of a Select Group of Seed Protectant Fungicides on Growth of Sclerotinia minor In Vitro and Its Recovery from Infested Peanut Seed
}

\author{
C. Bowen, Former Graduate Research Assistant, and H. A. Melouk, Research Plant Pathologist, USDA-ARS, De- \\ partment of Entomology and Plant Pathology; and K. E. Jackson, Assistant Extension Specialist, and M. E. Pay- \\ ton, Associate Professor, Department of Statistics, Oklahoma State University, Stillwater 74078-9947
}

\begin{abstract}
Bowen, C., Melouk, H. A., Jackson, K. E., and Payton, M. E. 2000. Effect of a select group of seed protectant fungicides on growth of Sclerotinia minor in vitro and its recovery from infested peanut seed. Plant Dis. 84:1217-1220.

Potato-dextrose agar containing $100 \mu \mathrm{g}$ of streptomycin sulfate per milliliter of medium (SPDA) was amended to establish levels of $0,2,4,6,8$, and $10 \mu \mathrm{g} / \mathrm{ml}$ of the fungicides thiophanatemethyl, carboxin, dicloran, captan, pentachloronitrobenzene (PCNB), or thiram. Fresh mycelial plugs, dry mycelial fragments, and sclerotia of Sclerotinia minor were placed onto the amended media, and mycelial growth and sclerotial germination were determined for 7 days. Thiophanate-methyl was the most effective chemical in inhibiting growth of $S$. minor, followed by PCNB and dicloran. Thiophanate-methyl was the only chemical that prevented germination of sclerotia of $S$. minor. Peanut seed naturally infested with $S$. minor was treated with the fungicides alone or in various combinations; control seed was treated with talcum powder. Seed was stored in polyethylene bags for 12 weeks at $24^{\circ} \mathrm{C}$. To determine the incidence of viable $S$. minor in treated seed, seed was removed from bags, washed for $1 \mathrm{~min}$ in $0.2 \%$ unscented, liquid soap solution, rinsed twice in distilled water, and then dried for $15 \mathrm{~min}$ prior to plating on SPDA. The incidence of $S$. minor in talcum and thiophanate-methyl treated seed was 3.68 and $0.0 \%$, respectively. Incidence of $S$. minor in seed treated with the other compounds ranged from 0.40 to $0.56 \%$. Subsequent tests were performed using thiophanate-methyl and some of the above chemicals, in combinations or alone. These tests confirmed that thiophanate-methyl was the only compound that consistently reduced recovery of $S$. minor from infested seed. Germination of thiophanate-methyl treated seed equaled that of seed treated with talcum.
\end{abstract}

Sclerotinia blight, caused by the soilborne pathogen Sclerotinia minor, is an important disease of peanut (Arachis hypogaea) in Oklahoma, where about $40 \%$ of the acreage was infested with $S$. minor, according to a grower survey conducted in 1998 by J. P. Damicone of Oklahoma State University. In susceptible peanut cultivars, yield losses of 30 to $50 \%$ due to Sclerotinia blight were reported (4). Typical symptoms of the disease include flagging, wilting, and necrosis of one or more stems (11). Stem lesions begin as a light tan color that turns dark brown; severely affected plants usually have shredded stems and discolored pods (11). Infected plant parts may

Corresponding author: H. A. Melouk

E-mail: hassan@okstate.edu

Reference in this publication to a trademark, proprietary product, or company name by personnel of the U.S. Department of Agriculture or anyone else is intended for explicit description only and does not imply approval or recommendation to the exclusion of others that may be suitable.

Accepted for publication 26 July 2000.

Publication no. D-2000-0912-01R

This article is in the public domain and not copyrightable. It may be freely reprinted with customary crediting of the source. The American Phytopathological Society, 2000. become covered with white, fluffy mycelium during periods of high humidity. Sclerotia, which are produced on and in infected plant stems and pods serve as overwintering inoculum (17).

Several modes of dissemination have been described for $S$. minor. Melouk et al. (9) found that up to $38 \%$ of the sclerotia recovered from fecal samples of a heifer fed peanut hay infested with $S$. minor were viable. Eclipta (Eclipta prostrata), a weed member of the Asteraceae that has been found in peanut fields in Oklahoma, was found to be susceptible to $S$. minor (8), and therefore, sclerotia produced on blighted Eclipta plants may serve as a source of $S$. minor inoculum. Peanut seed also may serve as a source of inoculum for the introduction of $S$. minor into uninfested fields (18). Akem and Melouk (1) showed that $S$. minor was seed transmitted under controlled greenhouse conditions and that transmission was genotype dependent. Peanut seed infested with $S$. minor was identified in a seed lot obtained from the Oklahoma Crop Improvement Association in 1989 (7). Usually, the incidence of $S$. minor in peanut seed harvested from fields with severe Sclerotinia blight ( $>50 \%$ of plants infected) is about $1 \%$.

Currently, there are no management practices available that effectively control Sclerotinia blight once it becomes estab- lished in a field. Two peanut cultivars, VA Bunch 81 and Tamspan 90, have moderate resistance to $S$. minor under field conditions in Oklahoma, Texas, and Virginia $(3,14)$. Iprodione, one of the two chemicals currently registered for control of Sclerotinia blight in peanut, is only moderately efficacious in reducing disease development in the field $(2,12)$. Therefore, emphasis must be placed on limiting introduction of the pathogen into uninfested areas.

$S$. minor survives in the form of sclerotia and/or dry mycelia in or on infested peanut seed. Porter et al. (12) found that $S$. minor incidence in seed of two peanut varieties (VA81B and Florigiant) was related to discoloration of seed testa and concluded that colonization of peanut seed with $S$. minor is restricted to mycelial infection of the seed testa.

In Ontario, Canada, a seed treatment containing diazinon, captan, and thiophanate-methyl was found to be effective in preventing the spread of white mold ( $S$. sclerotiorum) into uninfested fields by infested seed (16). Therefore, development of an effective and economical seed protectant may be of paramount importance in reducing the spread of $S$. minor on infested peanut seed. The objectives of this study were to determine the in vitro sensitivity of $S$. minor to a select group of fungicides, some of which are used as seed protectants on other crops, and to determine the efficacy of several of these seed protectant fungicides on reducing the recovery of $S$. minor from naturally infested peanut seed.

\section{MATERIALS AND METHODS}

Inoculum production. An isolate of $S$. minor, obtained from naturally infested 'Okrun' peanut seed in Oklahoma in 1989, was used throughout this study. The isolate was maintained in the dark at $22 \pm 2{ }^{\circ} \mathrm{C}$ on potato-dextrose agar (Sigma, St. Louis, MO), containing $100 \pm 2 \mu \mathrm{g}$ of streptomycin sulfate per milliliter of medium (SPDA).

Fresh mycelia of $S$. minor were produced by placing 15-mm-diameter mycelial plugs, taken from the leading edge of a 2-day-old culture of $S$. minor grown on SPDA, in the center of fresh plates of SPDA. Plates were incubated in the dark at $22 \pm 2^{\circ} \mathrm{C}$ for 2 days before use.

Dry mycelia of $S$. minor were produced by growing the fungus in potato-dextrose broth containing $100 \pm 2 \mu \mathrm{g}$ of streptomy- 
cin sulfate per milliliter of broth (SPDB) (5). SPDB was prepared by covering $200-\mathrm{g}$ washed, unpeeled potatoes with distilled water and autoclaving $\left(121^{\circ} \mathrm{C}\right)$ for $10 \mathrm{~min}$. The extract was strained through two layers of cheesecloth, $20 \mathrm{~g}$ of dextrose and $0.13 \mathrm{~g}$ of streptomycin sulfate $(77.5 \%$ a.i.) were added, and the volume brought to $1 \mathrm{~L}$ with distilled water. Fifty milliliters of SPDB was dispensed into 250-ml bottles and autoclaved for $15 \mathrm{~min}$. Each bottle was inoculated with a 15 -mm-diameter plug of fresh mycelia from the leading edge of a 2day-old culture of $S$. minor. Bottles were incubated on a table top, rotary shaker (15 rpm) at $22 \pm 2{ }^{\circ} \mathrm{C}$ for 5 days. Contents of five bottles were combined and centrifuged $(2000 \times \mathrm{g})$ at $4^{\circ} \mathrm{C}$ for $20 \mathrm{~min}$, the SPDB was decanted, and the fungal mycelia were suspended in a $5 \%$ aqueous solution of polyethylene glycol (MW 6000) and centrifuged as above. The mycelial mats were then placed on a 47-mm-diameter Millipore filter $(0.45-\mu \mathrm{m}$ pore size, Millipore, Bedford, MA), and excess liquid was removed by suction. Inoculum agar plugs were removed, and the mycelial mats were dried in a desiccator containing anhydrous $\mathrm{CaSO}_{4}$ (W. A. Hammond Drierite Co., Xenia, $\mathrm{OH}$ ) for $48 \mathrm{~h}$ at $22 \pm 2{ }^{\circ} \mathrm{C}$.

Sclerotia of $S$. minor were produced by placing 15-mm-diameter mycelial plugs, taken from the leading edge of a 2-day-old $S$. minor culture, at the center of fresh SPDA plates. Plates were incubated at $22 \pm$ $2^{\circ} \mathrm{C}$ in the dark for 2 weeks. Sclerotia were removed from the agar plates with tweezers, blotted with Whatman No. 1 filter paper (Maidstone, England), and used immediately.

Preparation of SPDA amended with seed protectant fungicides. Solutions of fungicides were prepared from concentrated stocks so that a total of $5 \mathrm{ml}$ of suspension (stock and/or distilled water) was added to each treatment flask containing SPDA. The SPDA was autoclaved for 20 min at $121^{\circ} \mathrm{C}$, cooled to $55^{\circ} \mathrm{C}$, and then doses of the following compounds were added to achieve concentrations of $0,2,4$, 6,8 , and $10 \mu \mathrm{g}$ a.i./ml: thiophanate-methyl (Topsin-M 46.2\% a.i., 4.5F, Gustafson, Dallas, TX), carboxin (Vitavax 34\% a.i., 3F, Gustafson), dicloran (Botran 75WP, NOR-AM [now Agrevo], Wilmington, DE), captan (Captan 50WP, Gustafson), pentachloronitrobenzene (PCNB) (Terraclor 75WP, Gustafson), and thiram (Arasan 75WP, Gustafson). Ten milliliters of amended medium was dispensed into each disposable petri dish $(15 \times 100 \mathrm{~mm})$, and dishes were used within 30 days of preparation.

Determination of mycelial growth and germination of sclerotia of $S$. minor on amended SPDA. Three experiments were conducted to determine the effects of the selected fungicides on growth of fresh and dry mycelia and on germination of sclerotia. Results from these experiments were used to formulate seed treatments for subsequent experiments.

The effect of fungicides on growth of mycelia was determined by placing a fresh mycelial plug (13-mm-diameter) of $S$. minor at the center of each of 10 plates per treatment. Each plate constituted a replication. Plates were incubated at $22 \pm 2^{\circ} \mathrm{C}$ in the dark, and growth was measured periodically for 7 days after plating. Plates were examined after 2 weeks for sclerotial production.

The effects of the fungicides on growth from dry mycelia was determined by placing dry mycelial fragments (approximately $2 \mathrm{~mm}^{2}$ ) at the center of each of 10 plates of SPDA amended medium. Plates were incubated as stated above, and mycelial growth was measured as described above.

To determine the effect of seed protectant fungicides on sclerotial germination, sclerotia of $S$. minor were surface sterilized in $0.53 \% \mathrm{NaClO}$ for $2 \mathrm{~min}$, blotted with Whatman No. 1 filter paper, and then plated, five sclerotia per petri dish, on each of 10 plates of SPDA amended medium. Plates were incubated at $22 \pm 2{ }^{\circ} \mathrm{C}$ in the dark and examined periodically up to 2 weeks for germination, mycelial growth, and production of new sclerotia.

Source of $S$. minor-infested seed. Seed of Okrun used in this study was produced during the 1989 and 1990 growing seasons in a field naturally infested with $S$. minor (sclerotial density of 2 to 5 per $100 \mathrm{~g}$ soil) at the Caddo Research Station near Ft. Cobb, OK. Peanut plots in both years had over 50\% incidence of Sclerotinia blight. Peanuts in both years were dug with a tworow digger/inverter 150 days after planting and kept in windrows for 3 days before harvest with a stationary thresher. Pods were dried to $10 \%$ moisture before shelling, and seed stored at about $5^{\circ} \mathrm{C}$ and $50 \%$ $\mathrm{RH}$ until used. Seed was sized on metal screens, and seed retained on a $6.7 \times 19.0$ $\mathrm{mm}$ screen were used in this study.

Treatment of seed with protectants. Seed-treatment fungicides included: captan (Captan 50WP); dicloran (Botran 75WP); Botec (Botec 60WP, Agrevo); carboxin (Vitavax 34\% a.i., 3F); thiram (Arasan 75WP); PCNB (Terraclor 75WP); and thiophanate-methyl (Topsin-M 46.2\% a.i., $4.5 \mathrm{~F})$. Fungicides were applied individually or in various combinations. Some mixtures included a seed protectant binder (Gustafson, Dallas, TX). Fungicides were applied at the rate of $2.5 \mathrm{~g}$ of fungicide per kilogram of seed in the form of flowables or dusts. Seed was coated with the various fungicides in a rotary bucket seed treater for $2 \mathrm{~min}$. In some experiments, seed were treated with the fungicides by mixing in plastic bags and gently agitating the contents for about $2 \mathrm{~min}$. Talcum powder (Gustafson) was used as a control treatment. Treated seed were stored in plastic bags at $22 \pm 2^{\circ} \mathrm{C}$ on a laboratory bench for
7 days prior to plating onto a nutrient medium.

Determination of the incidence of $S$. minor in treated seed. Treated seed was submerged and agitated in a $0.2 \%$ aqueous solution of unscented liquid soap (6) for 1 min to remove fungicides from the seed coat, then rinsed twice ( 1 min each) in deionized water. Seed was air dried for 15 min then plated onto SPDA. Five seeds were plated onto each petri dish $(15 \times 100$ $\mathrm{mm}$ ), unless otherwise specified. In one test, washed seed was split along the hypocotyl groove with the blunt edge of a pair of tweezers. The seed then was plated split-side down onto SPDA. Plates were incubated at $22 \pm 2^{\circ} \mathrm{C}$ in the dark and examined at 3-day intervals up to 2 weeks for presence of $S$. minor.

Statistical analysis. All statistical analyses were performed with PC SAS (SAS, Cary, NC), and treatment means were separated by the least significance difference test (15). Preliminary results indicated that thiophanate-methyl was the most effective fungicide in suppressing the growth of $S$. minor on SPDA. Therefore, analyses included a comparison of thiophanate-methyl with other fungicides.

Linear regression was used to determine and compare the effects of tested concentrations for each chemical (10). This analysis was used to determine if increasing the concentration of fungicides decreased the rate of growth of $S$. minor. The model used in the regression was: Growth of $S$. minor $\left(\right.$ area in $\left.\mathrm{mm}^{2}\right)=$ intercept $+(B 1 \times$ day $)+$ $(\beta 2 \times$ concentration $)+[B 3 \times($ day $\times$ concentration)].

A negative $B 3$ value indicates that the slopes at the higher concentrations are smaller than the slopes at the lower concentrations, or that the fungicide becomes more effective at higher concentrations.

Also, regression with dummy variables was used to compare the effect of thiophanate-methyl with the other fungicides individually (10). A fungicide was considered "more effective" than another if its slope (slope of the linear regression of area of growth on days of growth) was smaller than the slope associated with the other fungicide. This indicated that the growth of the fungus was inhibited by the fungicide. Regressions were performed for all fungicides in comparison to thiophanate-methyl, for all concentrations, and for fresh and dry mycelia.

Fungicides were compared by subtracting the slope of thiophanate-methyl from the slope of the comparison fungicide to determine the "slope difference." A negative slope-difference value indicated that the comparison fungicide was more effective than thiophanate-methyl, whereas a positive value indicated that thiophanatemethyl was more effective.

\section{RESULTS AND DISCUSSION \\ Effect of seed protectant fungicides on mycelial growth and germination of}


sclerotia of $S$. minor. Thiophanate-methyl, PCNB, and dicloran inhibited $(P=0.05)$ growth of $S$. minor from fresh and dry mycelia (Table 1). Overall, thiophanatemethyl was the most effective fungicide in suppressing growth from fresh and dry mycelia of $S$. minor, followed by PCNB, dicloran, and carboxin. Thiram and captan were least effective in inhibiting growth from fresh and dry mycelia of $S$. minor (Table 1)

Sclerotial germination of $S$. minor was completely inhibited by thiophanatemethyl at all concentrations tested. None of the other fungicides tested used in this test inhibited $(P=0.05)$ germination of sclerotia compared to the control at concentrations of up to $10 \mu \mathrm{g} / \mathrm{ml}$. Sclerotial germination ranged from 86 to $98 \%$ in the nonamended medium, whereas in media amended with all the seed protectant fungicides except thiophanate-methyl, sclerotial germination ranged from 74 to $100 \%$. Therefore, thiophanate-methyl appeared to be the only effective compound for reduction of the growth of $S$. minor and inhibition of the germination of sclerotia of S. minor.

Effect of seed protectants on the recovery of $S$. minor from infested seed. When protectant fungicides were applied to seed at a rate of $2.5 \mathrm{~g}$ of protectant per kilogram of seed, thiophanate-methyl was the only compound to completely inhibit the recovery of $S$. minor from naturally infested seed. Infection in the other treatments ranged from 0.32 to $0.56 \%$. All chemical treatments significantly reduced $(P=0.05)$ the recovery of $S$. minor from seed compared with the talcum-treated control; control seed had $3.68 \%$ infection. None of the treatments reduced seed germination compared to the control seed, but some treatments resulted in a significant increase $(P=0.05)$ in seed germination.

Due to the superior efficacy of thiophanate-methyl compared to the other compounds tested, subsequent tests tested the effect of thiophanate-methyl on the recovery of $S$. minor from naturally infested peanut seed. In peanut seed severely infested with $S$. minor, the pathogen may exist in or on seed as mycelia or sclerotia. Most infested seed appear healthy, with no physical sign of the pathogen. S. minor may exist in such seed near the surface or deep near the hypocotyl groove. If the fungus exists deep within the seed, splitting the seed and plating the split seed onto SPDA may increase isolation of $S$. minor by exposing more of the seed to the medium. Recovery of $S$. minor from seed was not affected by plating seed whole or split onto SPDA. Talcum-treated control seed

Table 2. Effect of selected fungicides on recovery of Sclerotinia minor from Okrun peanut seed plated whole or split onto a nutrient medium

\begin{tabular}{|c|c|c|c|}
\hline \multirow[b]{2}{*}{ Treatment $^{\mathrm{b}}$} & \multicolumn{3}{|c|}{ Recovery of $S$. minor $(\%)$ when seed plated ${ }^{\mathrm{a}}$} \\
\hline & Whole & Split & LSD $_{0.05}$ \\
\hline Talcum (control) & 2.40 & 2.00 & 2.2 \\
\hline Captan-dicloran-carboxin $^{c}$ & 1.00 & 0.40 & 1.4 \\
\hline Thiophanate-methyl (15\% a.i.) & 0.00 & 0.00 & 0.0 \\
\hline $\mathrm{LSD}_{0.05}$ & 1.20 & 1.64 & \\
\hline
\end{tabular}

${ }^{a}$ Treated seed were washed in $0.2 \%$ liquid soap and rinsed twice in deionized water. Washed seed was air dried for $15 \mathrm{~min}$ and plated whole or split, split side-down, onto potato-dextrose agar containing $100 \mu \mathrm{g}$ streptomycin sulfate per milliliter of nutrient medium (SPDA). Each treatment had 5 replications of 100 seeds each. Seeds were singly plated on SPDA plates $(15 \times 100 \mathrm{~mm})$. Plates were incubated at $22 \pm 2^{\circ} \mathrm{C}$ in the dark and examined every 3 days up to 2 weeks for presence of $S$. minor.

${ }^{\mathrm{b}}$ All treatments were applied in a bucket rotary seed treater for $2 \mathrm{~min}$ at a rate of $2.5 \mathrm{~g}$ protectant per kilogram of seed. Treated seed were incubated at $22 \pm 2^{\circ} \mathrm{C}$ on a laboratory bench for 1 week prior to plating.

${ }^{c}$ A mixture containing final concentrations of active ingredients of $27 \%$ captan, $25 \%$ dicloran, and $11 \%$ carboxin.

Table 3. Effect of seed protectants on the recovery of Sclerotinia minor from naturally infested Okrun peanut seed

\begin{tabular}{|c|c|c|c|}
\hline \multirow[b]{2}{*}{ Treatment $^{\mathrm{b}}$} & \multirow{2}{*}{$\begin{array}{l}\text { Weight }(\mathrm{g}) \text { of formulation } \\
\text { applied to } 1 \mathrm{~kg} \text { seed }\end{array}$} & \multicolumn{2}{|c|}{$\begin{array}{l}\text { S. minor recovery }(\%) \text { as } \\
\text { indicated on nutrient medium at }\end{array}$} \\
\hline & & Week 2 & Week 5 \\
\hline Talcum (control) & 0.00 & 2.7 & 2.7 \\
\hline Captan-dicloran $60-20^{\mathrm{c}}$ & 2.50 & 0.3 & 0.8 \\
\hline Thiophanate-methyl (15\% a.i.) & 2.50 & 0.0 & 0.0 \\
\hline Thiophanate-methyl ( $15 \%$ a.i.) & 1.88 & 0.0 & 0.0 \\
\hline $\operatorname{LSD}_{P=0.05}$ & & 0.7 & 0.7 \\
\hline
\end{tabular}

a Treated seed were washed in $0.2 \%$ liquid soap and rinsed twice in deionized water. Washed seed was air dried for $15 \mathrm{~min}$ and plated onto potato-dextrose agar containing $100 \mu \mathrm{g}$ streptomycin sulfate per milliliter of medium (SPDA). Each treatment had 5 replications of 200 seeds each. Five seeds were plated on each SPDA plate $(15 \times 100 \mathrm{~mm})$. Plates were incubated at $22 \pm 2{ }^{\circ} \mathrm{C}$ in darkness and examined every 3 days up to 5 weeks for seed positive for $S$. minor.

${ }^{\mathrm{b}}$ All treatments were applied in a bucket rotary seed treater for $2 \mathrm{~min}$. Treated seed were incubated at $22 \pm 2^{\circ} \mathrm{C}$ on a laboratory bench for 1 week prior to plating.

${ }^{c}$ A mixture containing final concentrations of active ingredients of $60 \%$ captan and $20 \%$ dicloran.

Table 1. Comparison of slope differences calculated from growth of fresh and dry mycelia of Sclerotinia minor on a nutrient medium amended with a select group of fungicides

\begin{tabular}{|c|c|c|c|c|c|c|}
\hline \multirow[b]{2}{*}{ Concentration $(\mu \mathrm{g} / \mathrm{ml})$} & \multirow[b]{2}{*}{ Hydration mycelia $^{b}$} & \multicolumn{5}{|c|}{ Slope difference of thiophanate-methyl compared to the following chemicals ${ }^{a}$} \\
\hline & & Carboxin & Dicloran & Captan & PCNB & Thiram \\
\hline \multirow[t]{2}{*}{2} & Fresh & -1.90 & -2.45 & 31.81 & 14.70 & 35.06 \\
\hline & Dry & 5.83 & -0.75 & 13.34 & 6.15 & 8.07 \\
\hline \multirow[t]{2}{*}{4} & Fresh & 6.52 & 4.45 & 38.88 & 6.92 & 40.84 \\
\hline & Dry & 8.38 & 1.66 & 18.60 & 3.97 & 7.67 \\
\hline \multirow[t]{2}{*}{6} & Fresh & 8.09 & 2.75 & 40.20 & 2.10 & 42.25 \\
\hline & Dry & 7.68 & 0.93 & 13.97 & 1.06 & 9.16 \\
\hline \multirow[t]{2}{*}{8} & Fresh & 7.94 & 2.67 & 37.38 & 1.64 & 46.29 \\
\hline & Dry & 6.35 & 1.39 & 18.74 & 0.54 & 14.07 \\
\hline \multirow[t]{2}{*}{10} & Fresh & 7.83 & 2.66 & 38.35 & 0.70 & 42.57 \\
\hline & Dry & 5.33 & 1.08 & 16.20 & 0.40 & 12.81 \\
\hline
\end{tabular}

a Slope difference is the slope associated with the comparison chemical minus the slope associated with thiophanate-methyl. A negative value indicated thiophanate-methyl was less effective than the comparison chemical. The slope of thiophanate-methyl was significantly different $(P=0.05)$ from the slope of any of the comparison chemicals at all concentrations. PCNB = pentachloronitrobenzene.

${ }^{\mathrm{b}}$ Fresh mycelial plugs (15-mm-diameter) or dry mycelia fragments were plated onto amended plates of potato dextrose agar containing $100 \mu \mathrm{g}$ streptomycin sulfate per milliliter. Each treatment consisted of 10 replicate plates. Slopes were determined from areas of mycelial growth of $S$. minor up to 7 days after plating. 
Table 4. Incidence of Sclerotinia minor in Okrun peanut seed treated with a mixture of fungicides containing thiophanate-methyl or talcum

\begin{tabular}{|c|c|c|}
\hline \multirow[b]{2}{*}{ Time lapsed $^{\mathrm{b}}$} & \multicolumn{2}{|c|}{ Incidence $^{\text {a }}(\%)$ of $S$. minor in seed treated witl } \\
\hline & Thiophanate-methyl mixture ${ }^{c}$ & Talcum \\
\hline $1 \mathrm{~h}$ & 0.00 & 1.40 \\
\hline 1 day & 0.10 & 2.00 \\
\hline 4 days & 0.00 & 2.60 \\
\hline 7 days & 0.00 & 1.80 \\
\hline 14 days & 0.00 & 2.90 \\
\hline $\operatorname{LSD}_{P=0.05}$ & 0.13 & 1.70 \\
\hline
\end{tabular}

a Seed were washed in $0.2 \%$ liquid soap and rinsed twice in deionized water, with a final soak for 1 $\min$ in $1.05 \% \mathrm{NaClO}$. Each treatment consisted of 5 replications of 200 seeds each. Five seeds were plated on each plate $(15 \times 100 \mathrm{~mm})$ with potato-dextrose agar containing $100 \mu \mathrm{g} / \mathrm{ml}$ streptomycin sulfate (SPDA). Plates were incubated at $22 \pm 2{ }^{\circ} \mathrm{C}$ in the dark and examined every 3 days up to 2 weeks for seed positive for $S$. minor.

${ }^{\mathrm{b}}$ Time lapsed between applying the treatment to seed and washing seed with water and liquid detergent to remove most of the chemical treatment before plating onto SPDA.

c Seed were treated with either a mixture containing $15 \%$ thiophanate-methyl, $40 \%$ captan, and $15 \%$ pentachloronitrobenzene (PCNB), or talcum at the rate of 2.5 g protectant per kilogram of seed. Treated seed were incubated at $22 \pm 2^{\circ} \mathrm{C}$ on a laboratory bench for the allotted time prior to washing and plating.

had $2.4 \%$ incidence of $S$. minor when plated whole and $2.0 \%$ incidence when plated split-side down onto SPDA (Table 2). The captan-dicloran-carboxin treatment reduced recovery to $1.0 \%$ when seed was plated whole and to $0.4 \%$ incidence when plated split. Thiophanate-methyl completely inhibited the recovery of $S$. minor when seed was plated whole or split. When treated seed were plated whole, both treatments significantly reduced $(P=0.05)$ the recovery of $S$. minor compared with the control, whereas only the thiophanatemethyl treatment significantly reduced $(P$ $=0.05$ ) the recovery of $S$. minor when seed was plated split. There was no difference observed in recovery of $S$. minor from seed with whole or split seed, so we were unable to associate the recovery of the fungus with the location of the fungus within the seed.

In two tests, reducing the rate of seed application of thiophanate-methyl from 2.5 $\mathrm{g}$ to $0.63 \mathrm{~g} / \mathrm{kg}$ seed made no difference in inhibition of $S$. minor. Seed germination ranged from 96 to $99 \%$ for the thiophanatemethyl treatment, compared with $98 \%$ for the talcum-treated control seed.

In one test, fungicide-treated seed was examined for growth of S. minor at 2 and 5 weeks after plating on SPDA. Incidence of $S$. minor in talcum-treated control seed remained at $2.7 \%$ at 2 and 5 weeks after plating (Table 3). The incidence of S. minor in seed treated with captan-dicloran $(60-20,2.5 \mathrm{~g} / \mathrm{kg}$ seed) was $0.3 \%$ after 2 weeks and $0.8 \%$ after 5 weeks. At rates of $15 \%$ a.i. thiophanate-methyl (2.50 and 1.88 $\mathrm{g} / \mathrm{kg}$ seed), complete inhibition of $S$. minor from seed was maintained for 5 weeks (Table 3). Seed germination ranged from 91 to $94 \%$ for the fungicide treatments, compared with $90 \%$ for the talcum control.

Seed treated with a formulation con- taining $10 \%$ a.i. thiophanate-methyl (2.5 $\mathrm{g} / \mathrm{kg}$ seed) did not completely inhibit reincidence of $S$. minor was $0.4 \%$, whereas formulations containing $15 \%$ a.i. of thiophanate-methyl resulted in complete inhibition in the recovery of $S$. minor from seed. These data suggest that thiophanatemethyl must be applied to seed at a concious in reducing the incidence of $S$. minor in seed.

When treated seed were stored for various lengths of time before washing and plating seed onto SPDA, thiophanatemethyl (15\% a.i., $2.5 \mathrm{~g} / \mathrm{kg}$ seed) completely inhibited the recovery of $S$. minor at all storage times, except at 1 day after treatment, where $0.1 \%$ infection was detected. The incidence of $S$. minor in thiophanate-methyl treated seed did not significantly differ $(P=0.05)$ across all storage times tested (Table 4), and was always lower than the control (Table 4).

Porter et al. (12) reported a $97.8 \%$ reduction in the incidence of $S$. minor in peanut seed after applying Botec at the rate of $2.5 \mathrm{~g} / \mathrm{kg}$ of seed. In our tests, formulations containing thiophanate-methyl (15\% of $S$. minor from naturally infested peanut seed by $99.5 \%$.

A seed treatment containing thiophanate-methyl, captan, and diazinon was reported to be effective in preventing the introduction of white mold of bean, caused by $S$. sclerotiorum, into uninfested fields in Ontario, Canada (13). In this study, thiophanate-methyl $(15 \%$ a.i.) in a mixture with other seed protectants proved to be an effective seed treatment against $S$. minor in peanut seed. A seed treatment containing $15 \%$ a.i. thiophanate-methyl would be economical and potentially effective in covery of $S$. minor from seed, where the centration of $15 \%$ a.i. to be most efficaa.i.) were effective in inhibiting recovery minimizing the spread of the pathogen. Identification of a seed treatment mixture containing thiophanate-methyl and other chemicals may also help to slow the development of resistant strains of S. minor in the field.

\section{LITERATURE CITED}

1. Akem, C. N., and Melouk, H. A. 1990. Transmission of Sclerotinia minor in peanut from infected seed. Plant Dis. 74:216-219.

2. Brenneman, T. B., Phipps, P. M., and Stipes, R. J. 1988. A rapid method for evaluating genotype resistance, fungicide activity, and isolate pathogenicity of Sclerotinia minor in peanut. Peanut Sci. 15:104-107.

3. Coffelt, T. A., Porter, D. M., and Mozingo, R. W. 1982. Registration of Virginia 81 bunch peanut. Crop Sci. 22:1085-1086.

4. Damicone, J. P., and Jackson, K. E. 1996. Disease and yield responses to fungicides among peanut cultivars differing in reaction to Sclerotinia blight. Peanut Sci. 23:81-85.

5. Melouk, H. A., and Bowen, C. 1990. Preparation of dry, viable mycelia of Sclerotinia minor. Phytopathology 80:1015.

6. Melouk, H. A., Bowen, C., and Aboshosha, S S. 1999. A procedure for isolation and determination of incidence of Sclerotinia minor in peanut seed. Alex. J. Agric. Res. 44:261-270.

7. Melouk, H. A., Bowen, C., and Jackson, K. E. 1990. Status of Sclerotinia minor in commercial peanut seed lots from Oklahoma. Proc. Am. Peanut Res. Educ. Soc. 22:40.

8. Melouk, H. A., Damicone, J. P., and Jackson, K. E. 1992. Eclipta prostrata, new weed host for Sclerotinia minor. Plant Dis. 76:101.

9. Melouk, H. A., Singleton, L. L., Owens, F. N., and Akem, C. N. 1989. Viability of sclerotia of Sclerotinia minor after passage through the digestive tract of a crossbred heifer. Plant Dis. 73:68-69.

10. Neter, J., Wasserman, W., and Kutner, M. H. 1983. Applied Linear Regression Models. Richard D. Irwin, Chicago, IL.

11. Porter, D. M. 1984. Sclerotinia blight. Pages 16-18 in: Compendium of Peanut Diseases. D. M. Porter, D. H. Smith, and R. RodriguezKabana, Eds. American Phytopathological Society, St. Paul, MN.

12. Porter, D. M., Taber, R. A., and Smith, D. H. 1989. The incidence and survival of Sclerotinia minor in peanut seed. Peanut Sci 16:113-115.

13. Smith, F. D., and Phipps, P. M. 1991. Agar plate, soil plate, and field evaluation of Fluazinam and other fungicides for control of Sclerotinia minor on peanut. Plant Dis. 75:1138-1143.

14. Smith, O. D., Simpson, C. E., Grichar, W. J., and Melouk, H. A. 1991. Registration of 'Tamspan 90' peanut. Crop Sci. 31:1711.

15. Steel, R. G. D., and Torrie, J. H. 1980. Principles and Procedures of Statistics, A Biometric Approach. McGraw-Hill, Inc., New York.

16. Tu, J. C. 1989. Management of white mold of white beans in Ontario. Plant Dis. 73:281285.

17. Wadsworth, D. F. 1979. Sclerotinia blight of peanuts in Oklahoma and occurrence of the sexual stage of the pathogen. Peanut Sci. 6:77-79.

18. Wadsworth, D. F., and Melouk, H. A. 1985. Potential for transmission and spread of Sclerotinia minor by infected peanut seed and debris. Plant Dis. 69:379-381. 